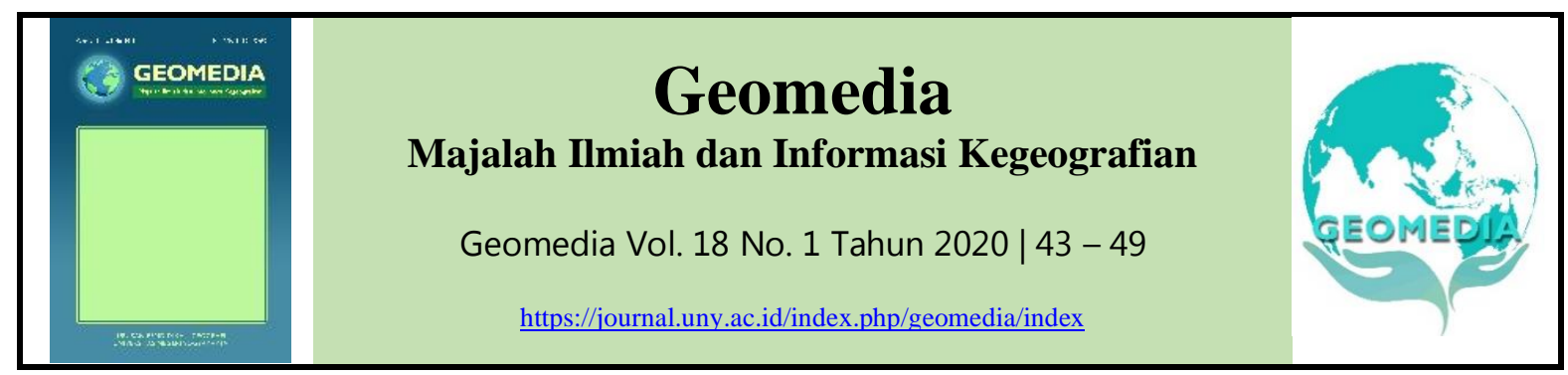

\title{
Analisis Sebaran dan Klasifikasi Usaha Kecil Menengah (UKM) Di Kabupaten Tegal
}

\author{
Gilang Rusadi Akhmad ${ }^{a, 1^{*}}$, Ari Susantiaji $i^{a, 2}$ \\ a Dosen Politeknik Muhammadiyah Tegal \\ ${ }^{1}$ gilangrusadiahmad88@gmail.com*; arysusan.as@gmail.com \\ *korespondensi penulis
}

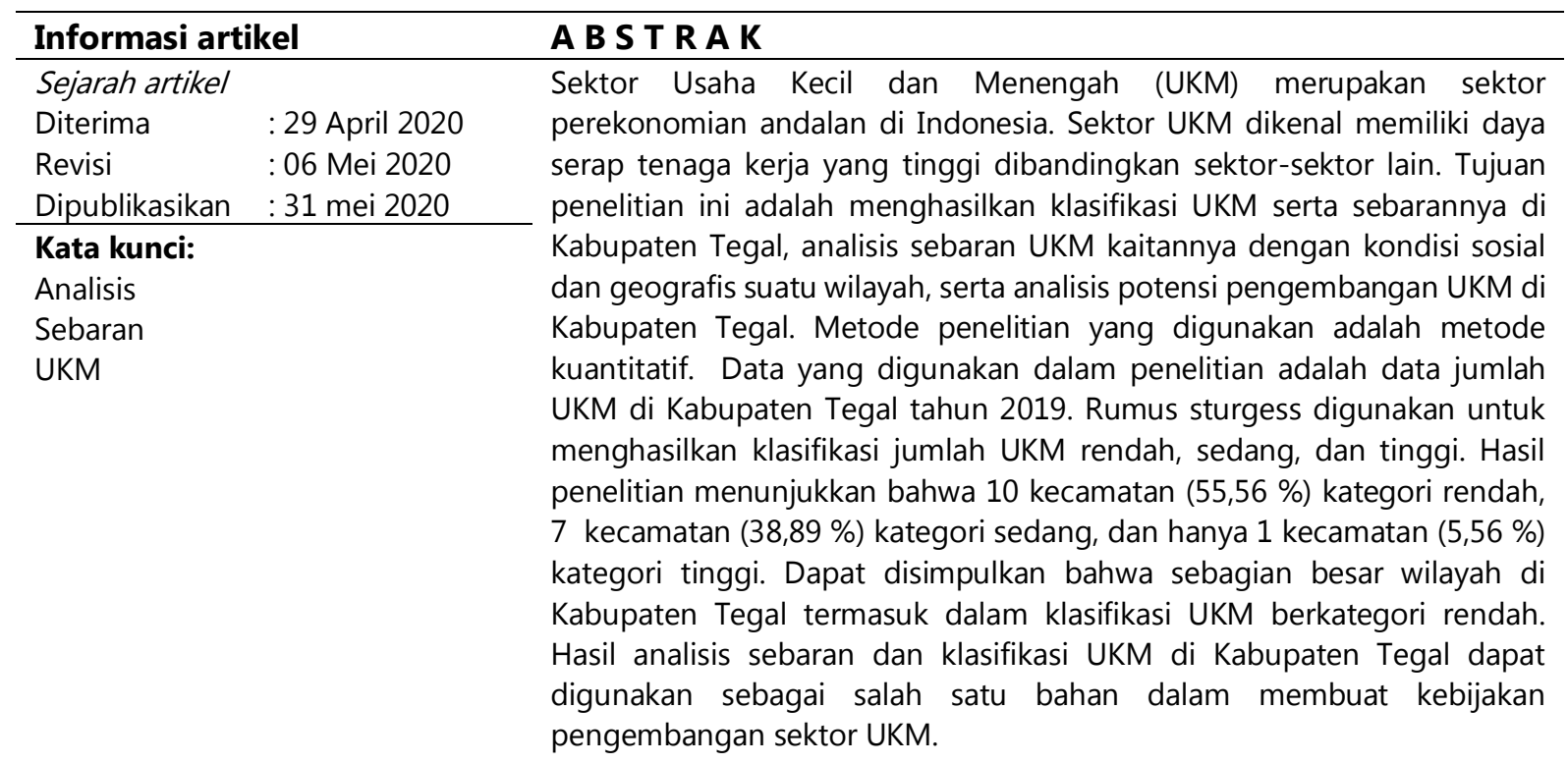

\section{Keywords:}

Analysis

Distribution

UKM

\section{A B S T R A C T}

The Small and Medium Enterprises (or called UKM in Indonesia) is a leading economic sector in Indonesia. The UKM sector is also known to have a high manpower absorption. The purpose of this study was to produce a classification of UKM and the distributin in Tegal Regency, analyze the distribution, as well as analyze the potential for developing UKM. The study used a quantitative method. The data used in the study is data on the number of UKM on 2019. The Sturgess Formula is used to produce a classification of the number consists from low, medium, and high UKM. The study results show that 10 sub-districts are in the low category, 7 sub-districts are in the medium category, and 1 sub-district is in the high category. The results of the study can be used as one of the indicators in making policies related to development of UKM sector.

(C) 2020 (Gilang Rusadi Akhmad \& Ari Susantiaji). All Right Reserved

\section{Pendahuluan}

Salah satu strategi yang dilakukan oleh pemerintah dalam menopang pembangunan ekonomi adalah dengan memberdayakan dan menumbuhkan Usaha Mikro, Kecil, dan Menengah (UMKM) sebagai dasar pembangunan ekonomi 
kerakyatan (Alyas dan M. Rakhib, 2017). Hal tersebut disebabkan sektor UMKM memiliki beberapa keunggulan salah satunya menurut Supriyanto (2006) adalah kemampuan bertahan menghadapi krisis ekonomi yang melanda Indonesia pada tahun 1997.

Selain terbukti mampu bertahan terhadap krisis ekonomi, menurut Permana (2017) UMKM juga memiliki peran yang sangat strategis dan penting dalam perekonomian Indonesia. Putra (2016) menyebutkan bahwa peran usaha mikro, kecil dan menengah (UMKM) dalam perekonomian Indonesia paling tidak dapat dilihat dari: (1) kedudukannya sebagai pemain utama dalam kegiatan ekonomi di berbagai sektor, (2) penyedia lapangan kerja yang terbesar, (3) pemain penting dalam pengembangan kegiatan ekonomi lokal dan pemberdayaan masyarakat, (4) pencipta pasar baru dan sumber inovasi, serta (5) sumbangannya dalam menjaga neraca pembayaran melalui kegiatan ekspor.

Karena besarnya peran UMKM dalam perekonomian, pemerintah telah membuat beberapa kebijakan yang menguntungkan sektor UMKM. Menurut Prasetyo (2019) kebijakan tersebut berupa penurunan pajak UMKM pemberian bantuan pemasaran dan pelatihan hingga penerapan Online Single Submission (OSS). Kebijakan-kebijakan tersebut terbukti berhasil membuat sektor UMKM tumbuh subur. Prasetyo (2019) menyebutkan bahwa rasio wirausaha di Indonesia pada tahun 2014 hanya 1,55\% kemudian pada tahun 2016 mengalami kenaikan menjadi $1,65 \%$. Puncaknya pada tahun 2017 melonjak nyaris dua kali lipat menjadi 3,1\%.

Kabupaten Tegal adalah salah satu kabupaten yang terletak di bagian barat laut Provinsi Jawa Tengah. Pertumbuhan sektor UMKM di Kabupetan Tegal mengalami kondisi pasang surut. Pada tahun 2011 terdapat 56.333 pengusaha kecil menengah, sedangkan tahun 2014 cenderung menurun yaitu sebanyak 29.134 pengusaha kecil menengah dengan jumlah tenaga kerja yang terserap 120.351 orang (Bappeda Kabupaten Tegal, 2015).
Pertumbuhan UMKM di Kabupaten Tegall memiliki potensi yang cukup besar disebabkan dua hal. Pertama, Kabupaten Tegal memiliki jalur transportasi yang strategis di persilangan arus transportasi Semarang-Cirebon-Jakarta dan Jakarta-Tegal-Cilacap yang dapat menjadi faktor pendukung pertumbuhan UMKM. Kedua, secara demografis, Kabupaten Tegal juga memiliki penduduk usia produktir (15-64 tahun) yang cukup besar sehingga bisa menjadi modal utama dalam meningkatkan pertumbuhan UMKM.

Pembangunan ekonomi wilayah dengan pendekatan geografi dan disajikan secara spasial kewilayahan dapat menjadi salah satu bahan kajian dalam perencanaan strategi untuk pengembangan potensi kewilayahan suatu daerah (Suherningtyas, 2019). Dibutuhkan analisis persebaran UKM di Kabupaten Tegal sebagai salah satu bahan pertimbangan dalam pengembangan sektor UKM. Analisis persebaran UKM di Kabupaten Tegal dilakukan dengan menampilkan jumlah UKM di Kabupaten Tegal dan kaitannya dengan kondisi sosial dan geografis suatu wilayah. Harapannya, melalui penelitian ini, pemerintah ataupun pihak-pihak terkait dapat menganalisis sebaran UKM di Kabupaten untuk mengoptimalkan UKM yang sudah ada dan memacu terbentuknya UKM-UKM baru.

\section{Metode}

Metode penelitian yang digunakan adalah metode kuantitatif sedangkan data dianalisis dengan metode deskriptif. Dalam penelitian deskriptif, objek penelitian dibiarkan apa adanya tanpa ada pemberian perlakuan khusus sehingga diperoleh gambaran aktual dan faktual objek penelitian (Suherningtyas, 2019). Objek penelitian adalah seluruh populasi UKM di Kabupaten Tegal.

Data yang digunakan adalah data jumlah UKM tahun 2019 dari Dinas Perdagangan, Koperasi, dan UKM Kabupaten Tegal. Data tersebut dibutuhkan untuk mengetahui jumlah UKM di tiap-tiap kecamatan di Kabupaten Tegal. Selanjutnya, data sekunder tersebut diolah dengan menggunakan metode sturges untuk 
mengklasifikasikan UKM di Kabupaten Tegal. Dengan metode sturges, dapat diketahui wilayah mana saja di Kabupaten Tegal dengan kategori UKM rendah, sedang, atau tinggi.

Data yang sudah diklasifikasikan, akan disajikan secara spasial dengan menggunakan software ArcGIS. Hasil yang diperoleh adalah pemetaan klasifikasi dan persebaran UKM di Kabupaten Tegal.

\section{Deskripsi daerah penelitian}

Kabupaten Tegal adalah salah satu kabupaten yang terletak di bagian barat laut Provinsi Jawa Tengah. Kabupaten Tegal secara geografis terletak pada koordinat $108^{\circ} 57^{\prime} 6^{\prime \prime}$ $109^{\circ} 21^{\prime} 30^{\prime \prime}$ BT dan 6 $50^{\prime} 41^{\prime \prime}-7^{\circ} 15^{\prime} 30^{\prime \prime}$ LS. Wilayah Kabupaten Tegal terdiri dari daratan seluas 878,7 $\mathrm{km}^{2}$ dan lautan seluas $121,50 \mathrm{~km}^{2}$.

Wilayah daratan mempunyai kemiringan bervariasi, mulai dari yang datar hingga yang sangat curam. Kemiringan lahan tipe datar / pesisir (0-20) seluas 24.547,52 ha (Kecamatan Kramat, Suradadi dan Warureja), tipe bergelombang / dataran (2-150) seluas 35.847,22 ha (Kecamatan Adiwerna, Dukuhturi, Talang, Tarub, Pagerbarang, Dukuhwaru, Slawi, Lebaksiu, sebagian wilayah Suradadi, Warureja, Kedungbanteng dan
Pangkah), tipe curam/ berbukit-bukit (15-400) seluas 20.383,84 ha dan tipe sangat curam / pegunungan $(>400)$ seluas 7.099,97 ha (Kecamatan Jatinegara, Margasari, Balapulang, Bumijawa, Bojong, sebagian Pangkah dan Kedungbanteng). Kondisi dataran tersebut, di antaranya berupa wilayah hutan, persawahan dan ladang yang cukup luas (Bappeda Kabupaten Tegal, 2015).

Secara administratif, Kabupaten Tegal memiliki 18 kecamatan (Margasari, Bumijawa, Bojong, Balapulang, Pagerbarang, Lebaksiu, Jatinegara, Kedungbanteng, Pangkah, Slawi, Dukuhwaru, Adiwerna, Dukuhturi, Talang, Tarub, Kramat, Suradadi dan Warureja), 281 desa, 6 kelurahan, 1.404 RW dan 6.746 RT (Bappeda Kab. Tegal, 2015).

Pembahasan tentang sektor UKM tidak dapat dilepaskan dari kondisi kependudukan suatu wilayah dimana sektor UKM tersebut berada. Manusia adalah pelaku sekaligus objek dalam sektor UKM. Gambar 1 menggambarkan perubahan jumlah penduduk yang terjadi di Kabupaten Tegal tahun 2016, 2017, dan 2018. Jumlah penduduk di Kabupaten Tegal selalu mengalami kenaikan dari tahun 2016 sampai 2018.

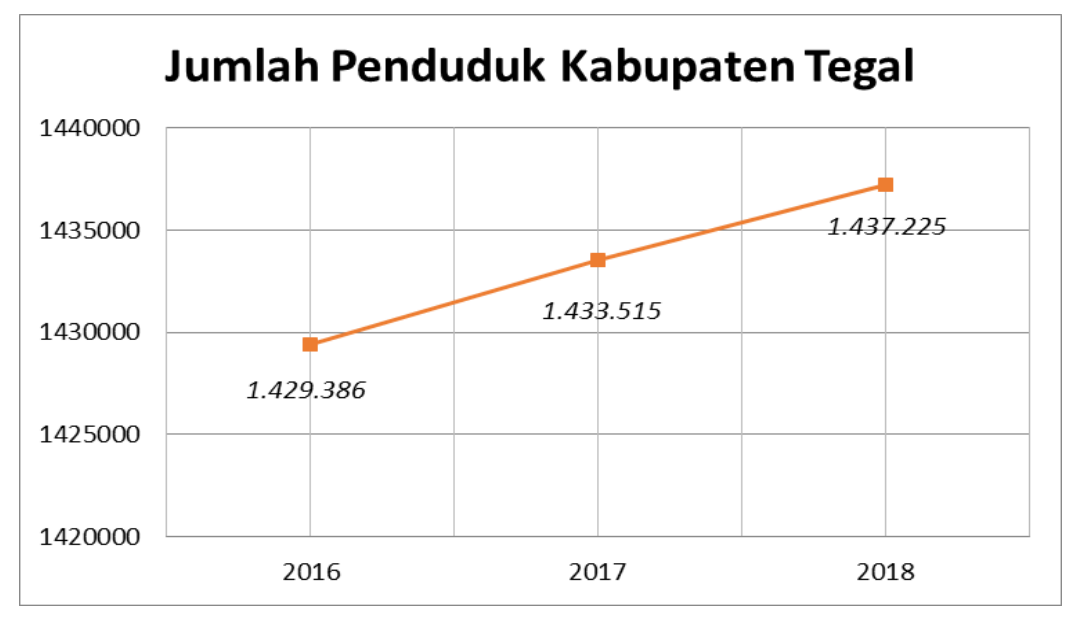

Gambar 1. Grafik jumlah pendudukan di Kabupaten Tegal tahun 2016, 2017, 2018

Jumlah penduduk di Kabupaten Tegal pada tahun 2016 mencapai 1.429.386 jiwa. Pada tahun 2017, jumlah penduduk di Kabupaten Tegal mengalami penambahan sebesar 4.129 jiwa sehingga menjadi 1.433.515 jiwa. Puncaknya, pada 
tahun 2018 penduduk di Kabupaten Tegal mencapai 1.437.225 jiwa.

Distribusi susunan penduduk Kabupaten Tegal pada usia tertentu disajikan secara grafis dalam piramida penduduk (Gambar 2). Berdasarkan Gambar 2 terlihat bahwa piramida penduduk di Kabupaten Tegal bertipe ekspansif. Hal tesebut tampak dengan cukup tingginya jumlah penduduk usia produktif (15-64 tahun). Jumlah penduduk usia produktif di Kabupaten Tegal masih cukup besar dibanding usia non produktif.

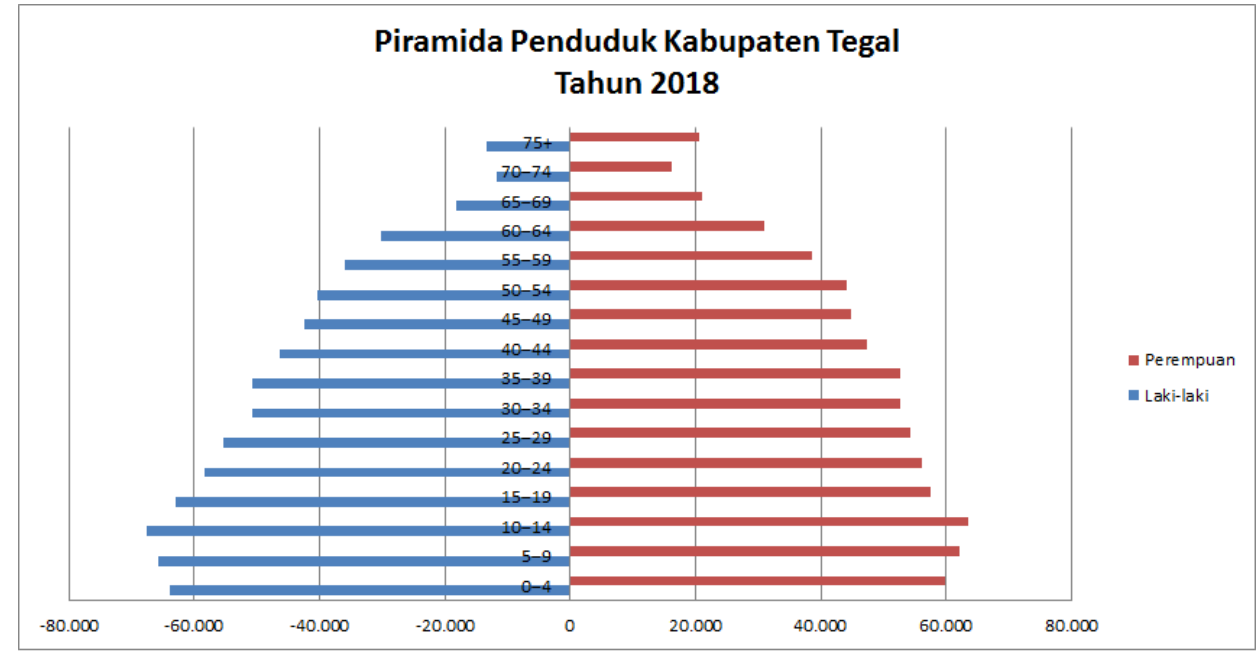

Gambar 2. Piramida penduduk Kabupaten Tegal tahun 2018

Secara umum, penduduk usia produktif yang dibekali dengan pendidikan dan keterampilan kerja berpotensi meningkatkan kemakmuran dan kesejahteraan masyarakat. Pemerintah Daerah Kabupaten Tegal juga perlu mempersiapkan lapangan kerja serta menjamin serapan tenaga kerja sehingga potensi penduduk usia produktif tersebut dapat tersalurkan dengan baik.

UKM adalah salah satu sektor yang perlu dikembangkan pemerintah Kabupaten Tegall karena terbukti memiliki serapan tenaga kerja yang tinggi. Sebagaimana dipaparkan oleh Putra (2016), sektor UKM memiliki peran penting dalam perekonomian bangsa karena merupakan penyedia lapangan kerja terbesar di Indonesia. Dengan berkembang dan tumbuhnya UKM dii Kabupaten Tegal diharapkan angka pengangguran di Kabupaten Tegal dapat berkurang.

\section{Hasil dan pembahasan}

Jumlah UKM Kabupaten Tegal tahun 2019 adalah 173.113. UKM tersebut tersebar tidak merata di 18 kecamatan. Jumlah dan sebaran UKM di Kabupaten Tegal diklasifikasikan dengan rumus sturgess sehingga menghasilkan wilayah dengan kriteria jumlah UKM rendah, sedang, dan tinggi (Tabel 1).

Tabel 1. Rentang klasifikasi jumlah UKM

\begin{tabular}{c|c}
\hline Kelas & Rentang Nilai \\
\hline Rendah & $3.960-9.958$ \\
Sedang & $9.959-15.957$ \\
Tinggi & $15.958-21.956$ \\
\hline
\end{tabular}

Hasil klasifikasi UKM dengan rumus sturgess menunjukkan bahwa sebanyak 10 kecamatan $(55,56 \%)$ kategori rendah, 7 kecamatan (38,89\%) kategori sedang, dan hanya 1 kecamatan (5,56 \%) kategori tinggi (Gambar 3). Dapat disimpulkan bahwa sebagian besar UKM (55,56 \%) di Kabupaten Tegal termasuk dalam kategori rendah.

Terdapat 10 kecamatan dengan kategori jumlah UKM rendah antara lain Kecamatan Bumijawa, Bojong, Balapulang, Pagerbarang, Lebaksiu, Jatinegara, Kedungbanteng, Suradadi, dan Warureja (Gambar 4). Jumlah UKM paling 
sedikit terdapat di Kecamatan Kedungbanteng sejumlah 3.961 UKM.

Sepuluh (10) kecamatan dengan kategori jumlah UKM rendah di Kabupaten Tegal merupakan kecamatan yang tidak mengandalkan sektor UKM sebagai roda penggerak perekonomian. Kecamatan-kecamatan tersebut lebih mengandalkan sektor pertanian atau pariwisata sebagai roda penggerak perekonomian daerah. Kecamatan Kedungbanteng dikenal sebagai kawasan pedesaan, 81,62 \% penduduk di Kecamatan Kedungbanteng bekerja di sektor pertanian (BPS Kabupaten Tegal, 2019). Hanya ada sekitar 18,38 \% penduduk yang bekerja di sektorsektor lain. Oleh karena itu jumlah UKM di Kecamatan Kedungbanteng paling rendah di antara kecamatan-kecamatan yang lain yakni 3.961 UKM.

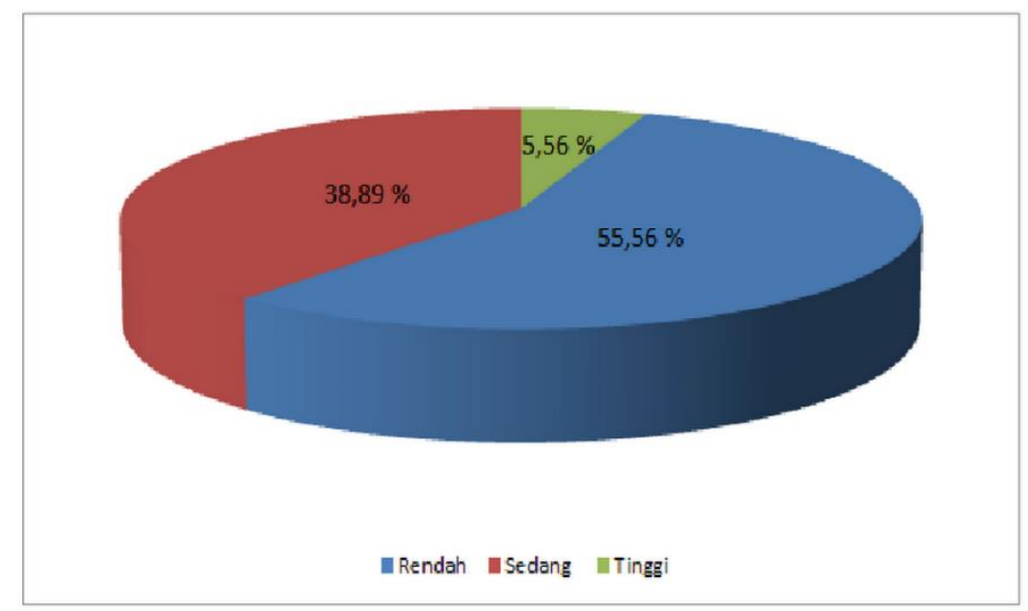

Gambar 3. Presentase UKM di Kabupaten Tegal

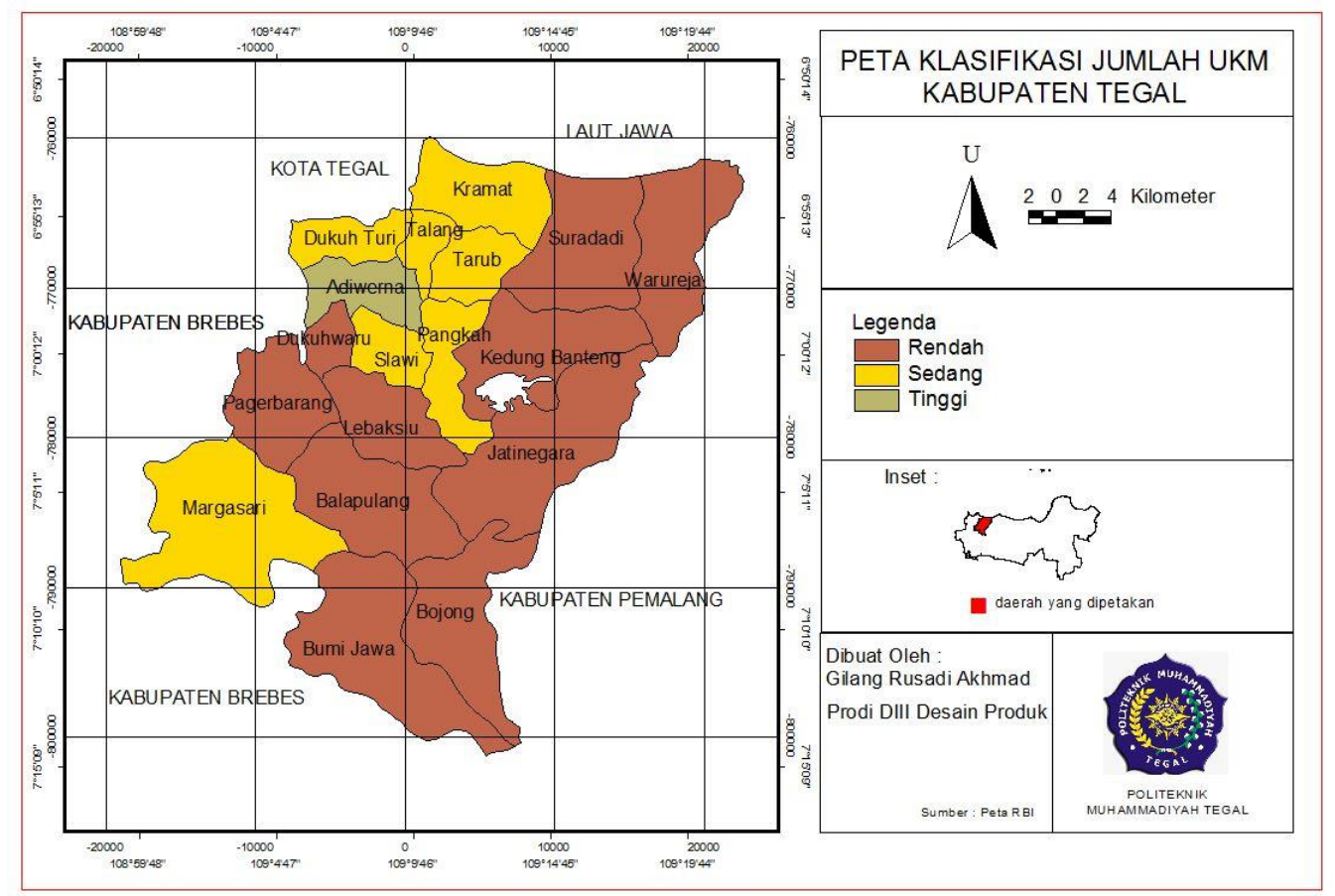

Gambar 4. Peta klasifikasi jumlah UKM di Kabupaten Tegal 
Kecamatan lain yang termasuk dalam kategori jumlah UKM rendah adalah Kecamatan Bumijawa. Kecamatan Bumijawa secara geografis terletak di lereng Gunung Slamet merupakan kecamatan yang mengandalkan sektor pertanian (BPS Kabupaten Tegal, 2019). Sektor pertanian mampu menyerap 79,08 \% tenaga kerja yang ada Kecamatan Bumijawa juga memiliki sektor pariwisata sebagai sektor andalan. Terdapat Obyek Wisata (OW) Guci yang terkenal di kalangan wisatawan domestik dengan pemandangan indah lereng Gunung Slamet serta pemandian air panasnya.

Kecamatan dengan kategori jumlah UKM tertinggi adalah Kecamatan Adiwerna dengan jumlah UKM sebanyak 21.955. Kecamatan Adiwerna merupakan kecamatan dengan jumlah penduduk terbesar di Kabupaten Tegal dengan 536 jiwa per km² (BPS Kabupaten Tegal, 2019). Sebagian besar penduduk di Adiwerna bekerja di sektor perdagangan dan industri. Kedua lapangan pekerjaan tersebut menyerap hingga 33,45 \% dan $31,62 \%$ pada tahun 2018. Tercatat 65,07 \% penduduk di Kecamatan Adiwerna bekerja di sektor perdagangan dan industri. Industri konveksi dan tekstil merupakan sektor UKM yang cukup terkenal di Kecamatan Adiwerna.

Hasil penelitian menunjukkan bahwa ada beberapa faktor yang bisa menjadi pendorong ataupun penghambat suatu daerah untuk menumbuhkembangkan sektor UKM. Salah satu faktor yang menentukan adalah kondisi geografis suatu wilayah. Sebagai contoh, Kecamatan Bumijawa yang terletak di lereng Gunung Slamet lebih mengandalkan sektor pertanian dan pariwisata karena kesuburan tanah dan pemandangan alamnya. Di sisi lain, Kecamatan Adiwerna yang berada di dataran rendah dan terletak di perkotaan maka mendorong sektor UKM untuk berkembang dan tumbuh subur.

Kondisi sosial dan budaya juga dapat menjadi salah satu faktor pendorong atau penghambat dalam mengembangkan sektor UKM di suatu wilayah. Kecamatan Kedungbanteng yang terletak di kawasan pedesaan sebanyak 81,62 \% penduduknya bekerja di sektor pertanian sehingga jumlah UKM di wilayah tersebut relatif kecil.

Upaya pengembangan sektor UKM di Kabupaten Tegal dapat diintegrasikan dengan sektor-sektor perekonomian yang lain. Sebagai contoh, sektor pertanian yang merupakan sektor andalan di Kecamatan Bumijawa dan Kecamatan Kedungbanteng dapat dikembangkan menjadi industri pertanian baik dengan skala kecil, menengah, ataupun besar. Melalui sentuhan teknologi dan inovasi dalam pengelolaan atau penyajian hasil pertanian maka sektor UKM juga dapat ikut berkembang di kecamatan-kecamatan tersebut. Sektor UKM perlu dikembangkan karena terbukti memiliki daya serap tenaga kerja yang cukup tinggi sehingga bisa meningkatkan kesejahteraan masyarakat. Melalui pelatihan softskill seperti teknik untuk mempromosikan sebuah produk serta manajemen keuangan maka sektor UKM dapat berkembang di Kabupaten Tegal.

Sektor UKM berpotensi untuk berkembang di Kabupaten Tegal dengan dua alasan. Pertama, pendudukan usia produktif di Kabupaten Tegal terbilang cukup besar. Penduduk usia produktif yang memiliki pendidikan dan keterampilan kerja dapat menjadi agen-agen penggerak perekonomian dan kemajuan masyarakat melalui sektor UKM. Kedua, Kabupaten Tegal memiliki posisi yang cukup strategis karena terletak di persilangan arus transportasi Semarang-CirebonJakarta dan Jakarta-Tegal-Cilacap dengan fasilitas pelabuhan di Kota Tegal. Potensi tersebut dapat dimanfaatkan untuk menumbuhkan dan mengembangkan UKM terutama di titik-titk transportasi yang strategis. Selain itu, posisi strategis tersebut juga memudahkan pemasaran produk UKM di Kabupaten Tegal untuk dipasarkan ke kota-kota lain.

\section{Simpulan}

Sektor UKM memiliki potensi yang cukup besar untuk tumbuh dan berkembang di Kabupaten Tegal karena dua alasan. Pertama, 
Kabupaten Tegal memiliki posisi yang cukup strategis di persilangan arus transportasi Semarang-Cirebon-Jakarta dan Jakarta-TegalCilacap. Kedua, Kabupaten Tegal memiliki jumlah penduduk usia produktif yang cukup besar yang diharapkan bisa menjadi agen penggerak perekonomian masyarakat.

Hasil kajian klasifikasi jumlah UKM di Kabupaten Tegal menunjukkan bahwa sebanyak 10 kecamatan (55,56\%) di Kabupaten Tegal berkategori rendah, 7 kecamatan (38,89 \%) berkategori sedang, dan hanya 1 kecamatan (5,56\%) berkategori tinggi. Hasil tersebut menunjukkan belum meratanya pertumbuhan UKM di Kabupaten Tegal.

Kajian persebaran UKM di Kabupaten Tegal ini dapat menjadi masukan dalam meyusun perencanaan dan pengambilan kebijakan berkaitan dengan perekonomian masyarakat. Sehingga diharapkan akan ada upaya peningkatan kualitas UKM melalui program-program yang bisa memacu pertumbuhan dan perkembangan UKM di Kabupaten Tegal.

\section{Ucapan terima kasih}

Penulis mengucapkan terima kasih kepada Politeknik Muhammadiyah Tegal yang telah memberikan dukungan penuh kepada penulis untuk menyelesaikan penelitian. Ucapan terima kasih juga dipersembahkan kepada Bappeda serta Dinas Perdagangan, Koperasi, dan UKM Kabupaten Tegal yang telah menyediakan datadata pendukung dalam penelitian.

\section{Referensi}

Alyas dan Mukhammad Rakhib. (2017). Strategi Pengembangan Usaha Mikro, Kecil, dan Menengah dalam Penguatan Ekonomi Kerakyatan (Studi Kasus pada Usaha Roti Maros di Kabupaten Maros). Sosiohumaniora. Vol 19 No 2. $114-120$

Bappeda Kabupaten Tegal. (2015). Narasi 8 (delapan) Kelompok Data Pengembangan Sistem Infromasi Profil Daerah Kabupaten
Tegal Tahun 2015. Cited in http://bappeda.tegalkab.go.id/. Diakses 3 Februari 2020

BPS Kabupaten Tegal. (2019). Jumlah Penduduk dan Laju Pertumbuhan Penduduk Menurut Kecamatan di Kabupaten Tegal 2016, 2017, dan 2018. Cited in https://tegalkab.bps.go.id/. Diakses 30 Oktober 2019

BPS Kabupaten Tegal. (2019). Kecamatan Adiwerna Dalam Angka 2019. Cited in https://tegalkab.bps.go.id/. Diakses 10 Maret 2020

BPS Kabupaten Tegal. (2019). Kecamatan Bumijawa Dalam Angka 2019. Cited in https://tegalkab.bps.go.id/. Diakses 11 Maret 2020

BPS Kabupaten Tegal. (2019). Kecamatan Kedungbanteng Dalam Angka 2019. Cited in https://tegalkab.bps.go.id/. Diakses 10 Maret 2020

Permana, S.H. (2017). Strategi Peningkatan Usaha Mikro, Kecil, dan Menengah (UMKM) di Indonesia. Aspirasi. Vol 8 No 1

Prasetyo, A. (2019). Kebijakan Pemerintah Bukti Keberpihakan kepada UKM. Cited in https://mediaindonesia.com/read/detail/ 211486-kebijakan-pemerintah-buktikeberpihakan-kepada-ukm. Diakses 3 Februari 2020

Putra, A. H. (2016). Peran UMKM dalam Pembangunan dan Kesejahteraan Masyarakat Kabupaten Blora. Jurnal Analisis Sosiologi. Vol 5 No 2. 40- 52

Suherningtyas, I.A. (2019). Analisis Spasial Persebaran Usaha Kecil Menengah di Kabupetan Sleman Daerah Istimewa Yogyakarta. Jurnal Geografi Vol 11 No. 101-107

Supriyanto. (2006). Pemberdayaan Usaha Mikro, Kecil, dan Menengah (UMKM) Sebagai Salah Satu Upaya Penanggulangan Kemiskinan. Jurnal Ekonomi \& Pendidikan. Vol 3 No 1 